\title{
MICROFIBRE REINFORCED HOT MIX ASPHALT
}

Josef Zak, Czech Technical University in Prague; Department of Road Structures; Thakurova 7, Prague, e-mail: josef.zak@ fsv.cvut.cz

Jiri Vavricka, Czech Technical University in Prague; Department of Road Structures; Thakurova 7, Prague, e-mail: jiri.vavricka@fsv.cvut.cz

\section{Abstract}

Cracks are common disturbances in pavement structure. The ability of hot mix asphalt to withstand tensile stresses is limited. This paper presents influence of different microfiber reinforcement types ITERFIBRA to hot mix asphalt behaviour in its chosen properties. Bulk density of hot mix asphalt, stiffness, resistance to the permanent deformation and resistance to the crack propagation are taken into consideration.

Keywords: microfiber reinforcement, stiffness, resistance to crack propagation, resistance to permanent deformation

\section{INTRODUCTION}

A process of material development starts by its genesis already or while its first application. The aim of the process is improvement of material qualities that have an influence on behaviour of construction. The improvement is achieved by lowering or total elimination of negative influence on prospective behaviour of construction without greater impact upon positive properties. The improvement of material qualities, which is achieved by admixture or ingredient, is conducted e.g. for lowering of construction and maintenance costs.

We want that the used materials, in highway construction, specifically the layers in road construction, will better resist the traffic load and climatic factor. In this case we can use the asphalt binder modification, surface reinforcement in contact of layers or three dimensional reinforcement for increasing of resilience. The advantage of three dimensional reinforcement in contradistinction to surface reinforcement is exclusion of both crack propagation (in bottom-up and topdown direction). It is due to resulting function of reinforcement. The surface reinforcement (geosynthetic) is anisotropic reinforcement and the tree dimensional reinforcement is an isotropic reinforcement of hot mix asphalts [1]. 
The main object of researched project was to provide an influence of different types of microfiber reinforcement ITERFIBRA to hot mix asphalt behaviour in this chosen properties:

- Bulk density of hot mix asphalt

- Stiffness

- Resistance to the permanent deformation

- Resistance to the crack propagation

In this paper we would like to present results of the comparative study on the Stone Mastic Asphalt SMA $11 \mathrm{~S}$ with respect to chosen properties, which have been done recently at the Faculty of Civil Engineering, Czech Technical University in Prague. The microfiber reinforcement ITERFIBRA type C, C/V and $\mathrm{C} / \mathrm{S}$ was used in hot mix asphalts taken under consideration. This microfibers effect as a stabilizer of binder. The dosing of microfibers and common used stabilizer (in no reinforced mixture), which is made by CIUR company as trade name S-CEL, was $0,33 \%$ of hot mix asphalt. The grain size curve of hot mix asphalt SMA $11 \mathrm{~S}$ is in figure \#1, with the inclusion of upper and lower passing restrictions according to CSN EN 13108-5 [8]. All mixes types were made with 50/70 asphalt binder. The percent binder content was $6.2 \%$ by mass of hot mix asphalt.

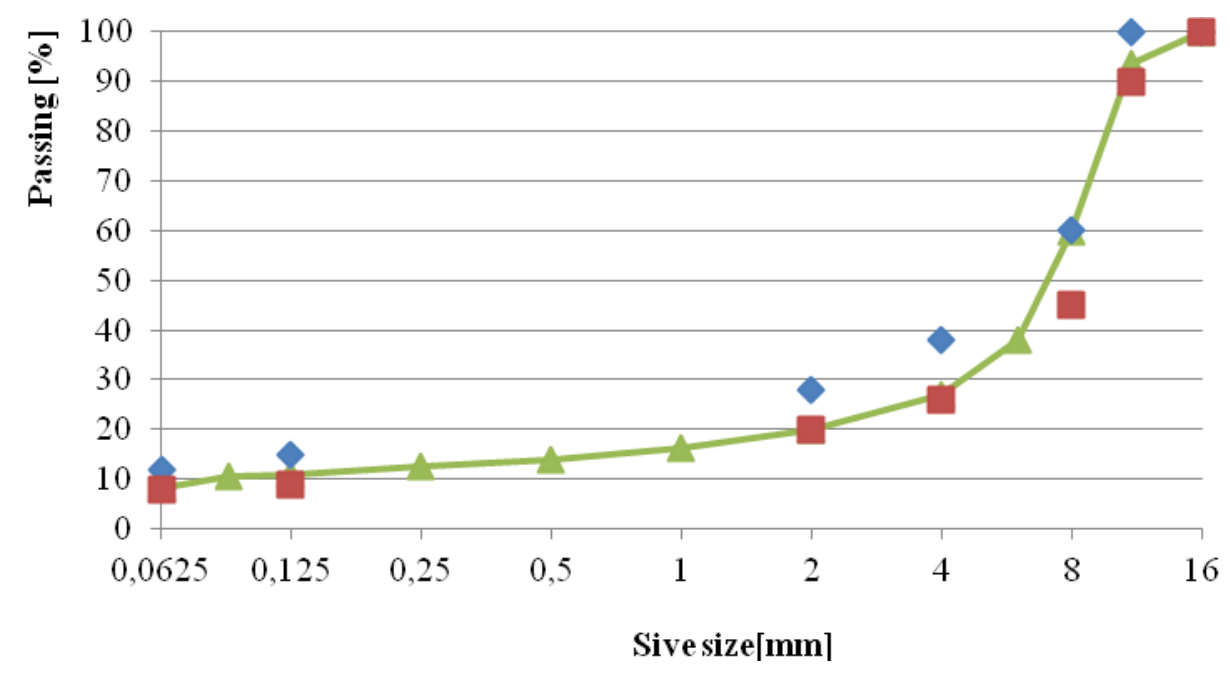

Figure 1. Grain size curve of SMA $11 \mathrm{~S}$

Summary of variants of hot mix asphalts SMA $11 \mathrm{~S}$ :

- SMA $11 \mathrm{~S}$

- FRSMA 11 S ITERFIBRA C

- FRSMA 11 S ITERFIBRA C/V 


\section{- FRSMA 11 S ITERFIBRA C/S}

\section{BULK DENSITY}

The average bulk density was determined from cylindrical specimens, which have been done by Marshall Hammer Compactor. The specimens was compacted by 50 strokes on both sides [8]. The specimen bulk density is determined according to procedure b) as indicated ČSN EN 12697-6+A1 [2]. We can see in the figure 2, that the mixtures with microfibers ITERFIBRA C/S and $\mathrm{C} / \mathrm{V}$ have lower bulk density than reference mixture (SMA $11 \mathrm{~S}$ ). The type $\mathrm{C}$ has similar bulk density $[1,2]$.

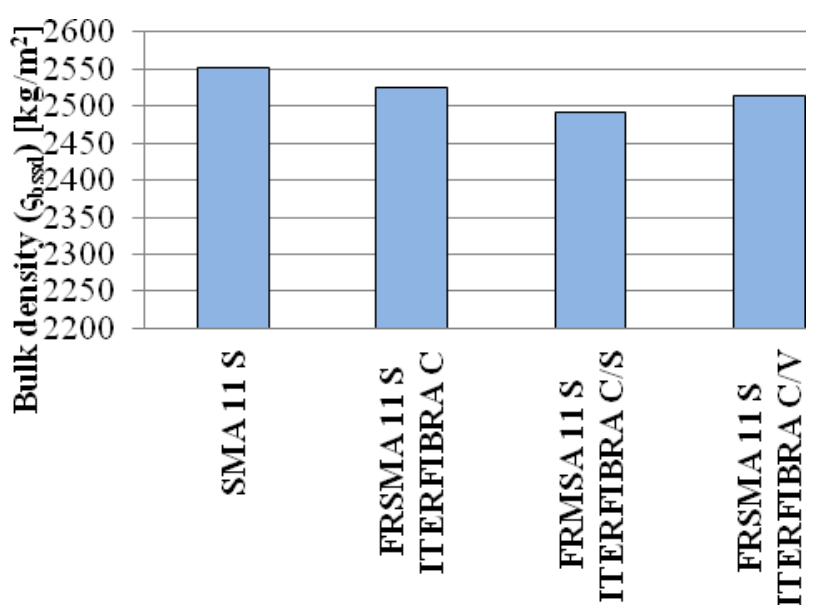

Figure 2. Bulk density of hot mix asphalts SMA $11 \mathrm{~S}$

\section{STIFFNESS}

In the study was used IT-CY method (indirect tensile test) using a cylindrical specimen with dimensions of $101.6 \times 62.5 \mathrm{~mm}$ according to [3]. Test temperatures were chosen at $0,15,27$ and $40^{\circ} \mathrm{C}$. The thermal sensitivity for assessed hot mix asphalts was determined. The thermal sensitivity is defined as a portion of stiffness at $0^{\circ} \mathrm{C}$ to stiffness at $40^{\circ} \mathrm{C}$ and is marked in the table 1 as $\tau$.

We can see that all hot mix asphalts with INTERFIBRA microfibres reached higher values of stiffness than reference hot mix asphalt at temperatures 15,27 and $40^{\circ} \mathrm{C}$. Comparable values have all mixes at temperature $0^{\circ} \mathrm{C}$. This trend is also documented with temperature sensitivity. All reinforced hot mix asphalts showed lower temperature sensitivity. Generally all tested mixes reached quite high stiffness values fulfilling the requirements given by the Czech Specification for pavement design TP170 [8]. 
ROMANIAN JOURNAL

\section{OF TRANSPORT INFRASTRUCTURE}

Josef Zak, Jiri Vavricka,

Microfibre reinforced Hot Mix Asphalt

Table 1. Stiffness data of hot mix asphalts

\begin{tabular}{|c|c|c|c|c|c|c|c|}
\hline \multirow{2}{*}{$\begin{array}{c}\text { Test } \\
\text { temperature }\end{array}$} & SMA11 S & \multicolumn{2}{|c|}{$\begin{array}{c}\text { FRSMA 11 S } \\
\text { ITERFIBRA C }\end{array}$} & \multicolumn{2}{|c|}{$\begin{array}{c}\text { FRSMA 11 S } \\
\text { ITERFIBRA C/V }\end{array}$} & \multicolumn{2}{|c|}{$\begin{array}{c}\text { FRSMA 11 S } \\
\text { ITERFIBRA C/S }\end{array}$} \\
\cline { 2 - 8 } & $\mathrm{E}$ & $\mathrm{E}$ & $\begin{array}{c}\text { Change of } \\
\mathrm{E} \\
{\left[{ }^{\circ} \mathrm{C}\right]}\end{array}$ & $\mathrm{E}$ & $\begin{array}{c}\text { Nárůst E } \\
{[\%]}\end{array}$ & $\begin{array}{c}\mathrm{E} \\
{[\mathrm{MPa}]}\end{array}$ & $\begin{array}{c}\text { Change of } \\
\mathrm{E} \\
{[\%]}\end{array}$ \\
\hline 0 & 23038 & 23578 & 2,3 & 23208 & 0,7 & 22402 & $-2,8$ \\
\hline 15 & 10745 & 12140 & 13,0 & 11267 & 4,9 & 12974 & 20,7 \\
\hline 27 & 3738 & 5077 & 35,8 & 4823 & 29,0 & 6898 & 84,5 \\
\hline 40 & 1090 & 1520 & 39,5 & 1348 & 23,7 & 2636 & 141,9 \\
\hline$\tau$ & 21,15 & 15,51 & & 17,22 & & 8,50 & \\
\hline
\end{tabular}

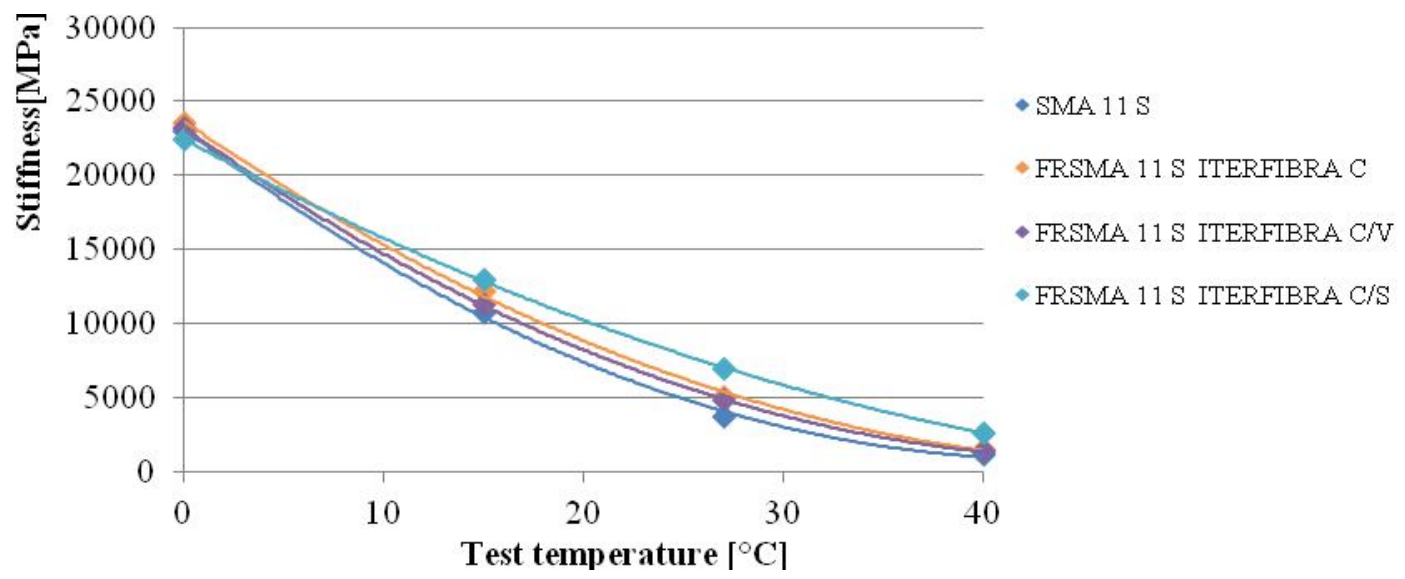

Figure 3. Stiffness data of hot mix asphalts

\section{WHEEL TRACKING TEST}

The resistance of mixtures to permanent deformation was measured with Hamburg-Wheel Tracking Test method according to ČSN EN 12697-22+A1. The test procedure was done at small test device-procedure B in accordance with standard. The specimen was tempered with air to temperature $50^{\circ} \mathrm{C}$. The values as a rut depth at 10000 cycles (PRDair) and rut depth increment between 5000 and 10000 cycles (WTSair) characterize the permanent deformation resistance. The influence of microfibers ITERFIBRA $\mathrm{C}$ and $\mathrm{C} / \mathrm{V}$ to permanent deformation resistance was not proved. The type of microfibers $\mathrm{C} / \mathrm{S}$ has negative effect on permanent deformation resistance (see below chart 4 and 5). [1,5] 
ROMANIAN JOURNAL

\section{OF TRANSPORT INFRASTRUCTURE}

Josef Zak, Jiri Vavricka,

Microfibre reinforced Hot Mix Asphalt

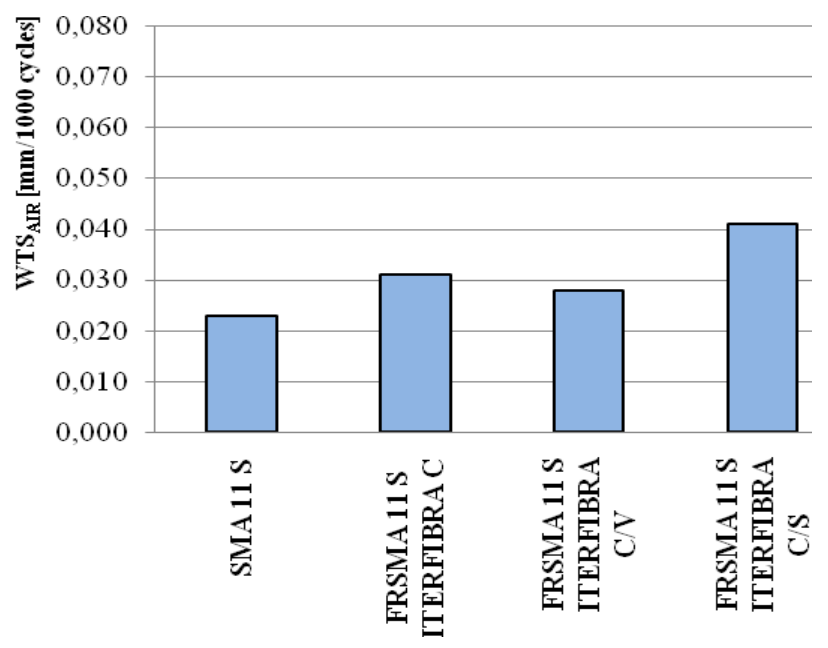

Figure 4. WTS AIR $_{\text {of SMA } 11 \mathrm{~S}}$

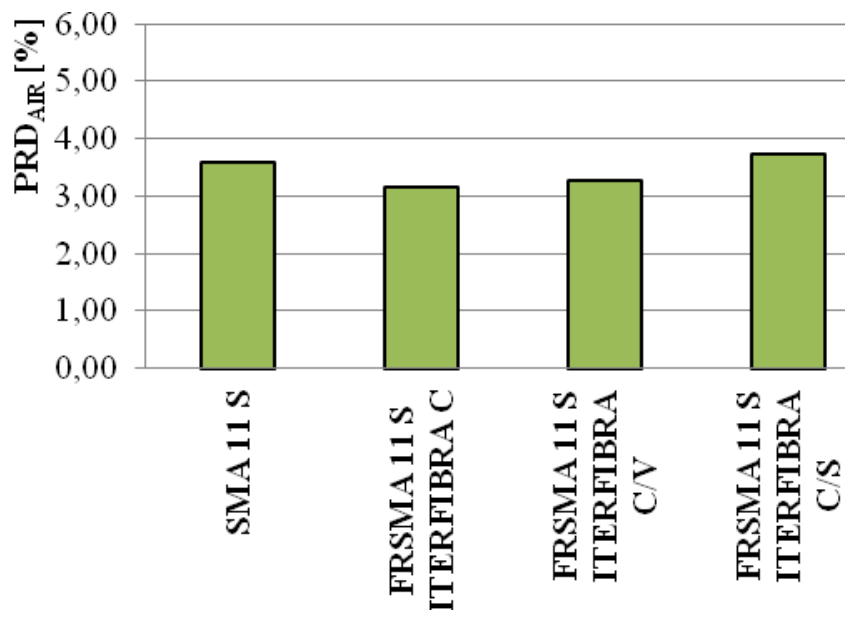

Figure 5. PRD $\mathrm{AIR}_{\mathrm{A}}$ of SMA $11 \mathrm{~S}$

\section{RESISTANCE TO CRACK PROPAGATION}

The resistance to crack propagation was measured in accordance with ČSN EN 12697-44, which will be soon in force. The resistance is measured on semi-cylindrical specimen with groove in the middle. The load is applied in three areas on the tested specimen (three point bending) so that the middle lower face of tested specimen is subject to tension. The bend is caused by applied constant increment of strain deformation. During the test is the force and deformation automatically recorded.. The resistance to crack propagation is based on the maximum load (Fmax) that the material containing a groove can resist before failure $(\mathrm{Klc})$. This paper is aimed to residual strength moreover, 
ROMANIAN JOURNAL

\section{OF TRANSPORT INFRASTRUCTURE}

Josef Zak, Jiri Vavricka,

that is expressed as work (RW), which the test device performs to achieve 50\% of Fmax. The tests were conducted by temperatures $0^{\circ} \mathrm{C}$. The reinforced hot mix asphalts with microfibers ITERFIBRA did not prove better resistance to crack propagation or crack creation as was expected on the basis of parameters under consideration (figure 6 and 7). Inasmuch as this is a new test procedure and for the same reason, the experience is on the same level in others European countries, it is necessary to acquire experience in this test procedure and verify the results in order to correct results explicate $[1,6]$.

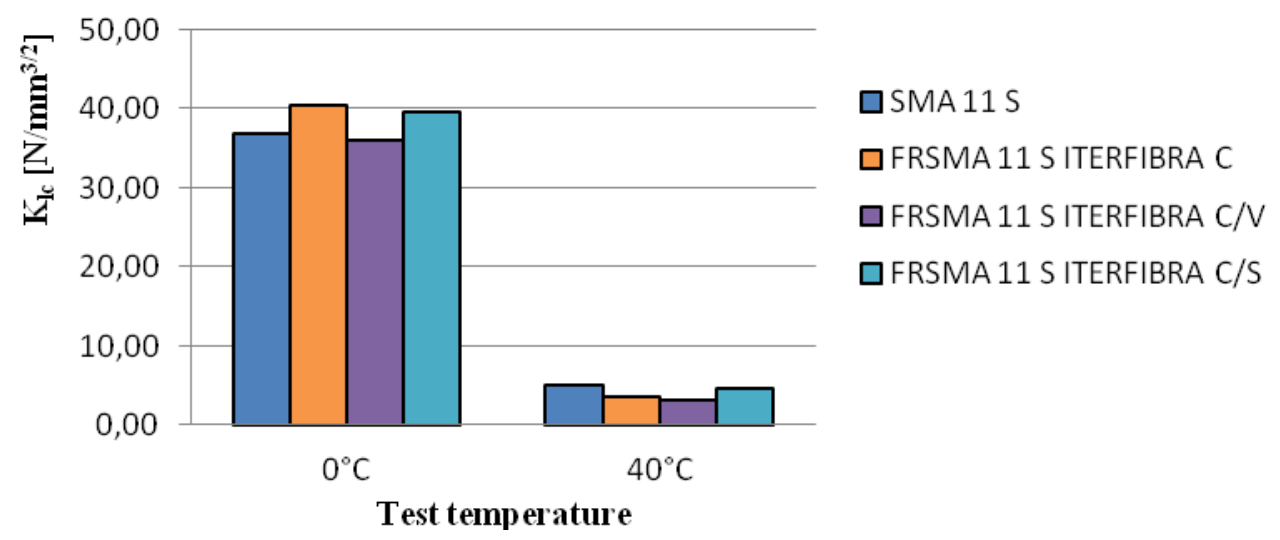

Figure 6. $\mathrm{K}_{\mathrm{lc}}$ of SMA $11 \mathrm{~S}$

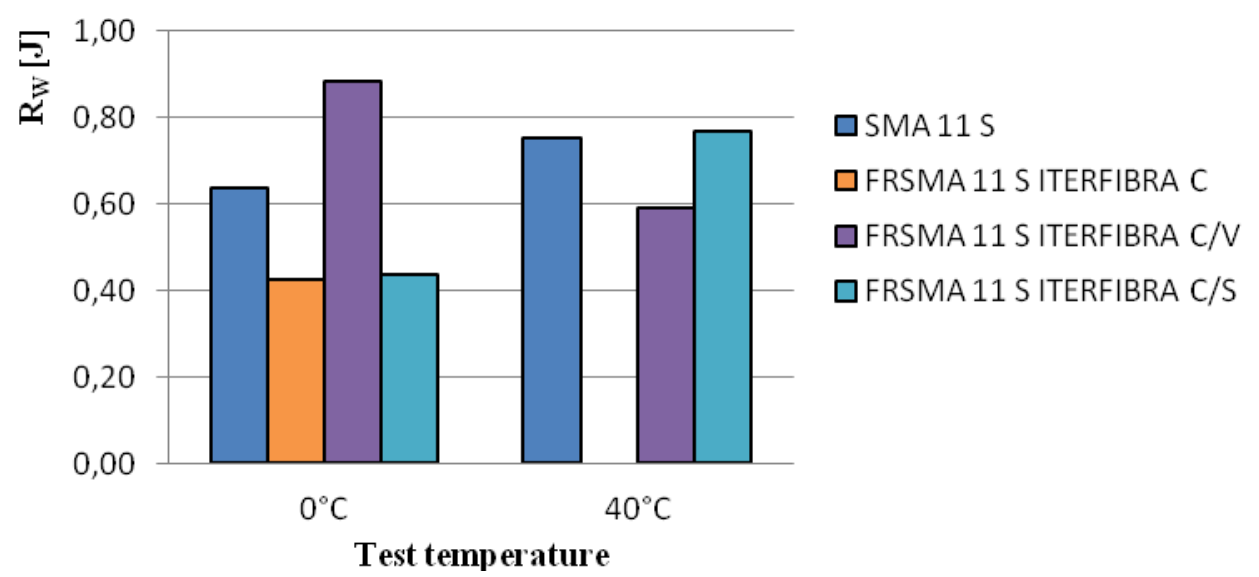

Figure 7. $\mathrm{R}_{\mathrm{W}}$ of SMA $11 \mathrm{~S}$ 
ROMANIAN JOURNAL

\section{OF TRANSPORT INFRASTRUCTURE}

Josef Zak, Jiri Vavricka,

Microfibre reinforced Hot Mix Asphalt

\section{CONCLUSIONS}

The summary of paper findings for individual microfibers ITERFIBRA[1]:

- Type C

- Bulk density of hot mix asphalt specimen - any influence

- StiffneSs - positive influence

- Permanent deformation resistance - any influence

- Crack propagation resistance - any influence

- Type $\mathrm{C} / \mathrm{V}$

- Bulk density of hot mix asphalt specimen - lower the bulk density of specimen which has been made by Marshall Hammer Compactor

- Stiffness - positive influence

- Permanent deformation resistance - any influence

- Crack propagation resistance - any influence

- Type $\mathrm{C} / \mathrm{S}$

- Bulk density of hot mix asphalt specimen - lower the bulk density of specimen which have been made by Marshall Hammer Compactor

- Stiffness - positive influence

- Permanent deformation resistance - has negative influence

- Crack propagation resistance - any influence

The article was supported by the project SGS 12/040/OHK1/1T/11.

\section{REFERENCE}

[1]. Jiri Vavricka; Fibres in hot mix asphalts; Diploma thesis, 2010

[2]. CSN EN 12697-6+A1; Bituminous mixtures - Test method for hot mix asphalt-Part 6: Determination of bulk density of bituminous specimens; Czech office for standards, metrology and testing; 2007

[3]. CSN EN 12697-26; Bituminous mixtures - Test method for hot mix asphalt-Part 26: Stiffness; Czech office for standards, metrology and testing; 2006

[4]. CSN EN 13108-20; Bituminous mixtures - Material specifications-Part 20: Type testing; Czech office for standards, metrology and testing; 2008 
ROMANIAN JOURNAL

\section{OF TRANSPORT INFRASTRUCTURE}

Josef Zak, Jiri Vavricka,

Microfibre reinforced Hot Mix Asphalt

[5]. CSN EN 12697-22+A1; Bituminous mixtures - Test method for hot mix asphalt-Part 22: Wheel tracking; ; Czech office for standards, metrology and testing; 2007

[6]. CSN EN 12697-44; Bituminous mixtures - Test method for hot mix asphalt-Part 44: Crack Propagation by Semi-circular Bending Test; Czech office for standards, metrology and testing; 2010

[7]. TP 170; Specification for pavement design; September 2006

[8]. CSN EN 13108-5; ; Bituminous mixtures - Material specifications-Part 5: Stone Mastic Asphalt; 2008 